\title{
Understanding Social Interaction with Human Computer Interaction (HCI) Adaptation
}

\author{
W. V. Siricharoen ${ }^{1, *}$ \\ ${ }^{1}$ Faculty of Information and Communication Technology \\ Silpakorn University, Nonthaburi, Thailand, 11120
}

\begin{abstract}
Human computer interaction (HCI) is an initial study that people use complex technological inventions. The secondary focus, but more importantly, is the strategy of these inventions to smooth this use. HCI is what happens when users and computers system get together to accomplish something. The paper will propose the idea of people involve with HCI in the way of making their life change. The brief of HCI research aspect is revisited in the introduction. The social interaction and social media are addressed. Also, the paper discusses the changing in daily life with technology. The paper shows the impact of the technology on the way people communicate and change in work and social habits.
\end{abstract}

Keywords: HCI, Social Interaction, User, Social Media, Technology

Received on 19 June 2019, accepted on 02 July 2019, published on 20 August 2019

Copyright (C) 2019 W. V. Siricharoen licensed to EAI. This is an open access article distributed under the terms of the Creative Commons Attribution license (http://creativecommons.org/licenses/by/3.0/), which permits unlimited use, distribution and reproduction in any medium so long as the original work is properly cited.

doi: 10.4108/eai.13-7-2018.160762

$\overline{{ }^{*} \text { Corresponding author. Email:siricharoen_w2@su.ac.th }}$

\section{Introduction}

"Humans are social animals" by Elliot Aronson [20], a world-renowned social psychologist, notes the principle of nature of being human in his book. Human perceptions are adapted to our social context. For example, [1] the perception helps us to be aware of the feelings and actions of others, or the human auricle that adapts to the human voice better than other sounds. [2] Social interaction is a significant part of human perceptions and we can define social meanings for whatever other people do around us. [3] One of the explanations is the scientific hypothesis. [4] The theory that social environment, and our relationship is the driving force in the development of complex human brain. According to this theory, competition and cooperation make our development so profound that all our behavior is formed for social survival.

Human computer interaction (HCI) and social psychology is the study of interaction between humans/users and computers. It is a study that relates to many fields, such as computer science, behavioral science, psychology, and design, etc. HCI consists of 3 main components, which are users, computers, and ways to make these two elements work together; it is interaction [21].

- Users

The users or group of the users in HCI mean, who are working together and will carry the user's perception (such as vision, hearing, and touch) to control the transmission of information. It will be different according to each user's attitude or the principles of different usage requirements. It is different according to the ability to learn and the present knowledge, together with natural and cultural differences of each user.

- Computers

When we think of computers, we think of technology in the scope of the Personal Computer or Laptop. The computers are mentioned here, they mean the various systems with extensive scope, including machinery and various automation systems. The computer can do the basic tasks as well as complex tasks to make life and work easier. Computers can be referred as the small computer, to the large computer systems. It may be a website or as devices such as tablets, notebooks, MacBook, and smartphones. 


\section{- Interaction}

Since people and machines are very different, $\mathrm{HCI}$ is the field that allows both to work together as a fully functional system. Therefore, HCI must be developed with the ability to recognize the stimulation of human beings. Users are able to pass commands that allow the computer to work as needed. The interaction between computers and users occurs at the user interface in both software and hardware, as follows.

- Characters or objects displayed on the screen of the computer through the software.

- Receiving data from users through input or hardware that is peripheral of the computer such as keyboard and mouse.

- Interaction with users in large computer systems, such as a plane or a power plant.

In addition, there are many theories that are invented to understand the interaction between computers and humans. These theories can be divided into 3 groups:

The first group explores the interaction between computers and humans as the form of data processing, such as Fitts 'Law, GOMS models etc.

The second group explores the action-oriented interactions of those who focus on the project, such as activity theory and so on.

The third group explores interactions related to social and object-oriented contexts, such as distributed intelligence theory.

ACM has defined HCI as a knowledge relates to the design, evaluation, and implementation of human computer interaction systems. Therefore, it is the study of various phenomena associated. HCI is also the study of how humans interact with computers. Also, we consider what factors can make the computer interact with humans successfully. In summary, HCI means studying and analyzing interactions between computer devices or computer system with users.

Computer-Human Interaction (CHI) may be translated as interaction of the computer which responses to the user. This field has its roots in many areas of sciences, especially the human factors (Ergonomics). Similarly, it is related to other areas including psychology, anthropology, physiology, social sciences, engineering, computer science, and management, etc.

One area has a strong relationship with HCI is Computer Supported Collaborative Work (CSCW) which is interested in the interaction between the computer and the user in the context of the group. Using computer systems in this group is called Groupware. The main idea of HCI research is the development of technology to support the work of others. Because [22] The key to design discipline is the concept of "usability" which is often defined in terms of efficiency, effectiveness and satisfaction. The study of the suitability of the computer system to users is "Usability Study". The term usability is used by human computer engineering to study artifacts for users such as hammers, cruisers, audio instruments, control panels, and traffic lights etc. However, it is similarly significant or designed for individual use.

Questions and issues of HCI research have been continuously developed. To understand human behavior on various issues, such as the issue of "usability" as the starting point and the center of research. At the beginning, the issue of "usability" was simply defined as being easy to learn or easy to use. However, now usability has evolved into meaningful, covering more diverse issues, such as fun, better creativity, supporting human development, etc. Therefore, the ability to explore the development of HCI knowledge in the work cycle - equipment, tools, task-artifact cycle. Starting with the study of user behavior and the nature of work that users perform. It is to develop technology as a working tool to achieve the goal of human need. Subsequently, studying the use of those technologies. It is also to improve the technology to be appropriate for the user.

Many rely upon HCI for the purposes of everyday life and for solutions for worldwide problems. Each step in the expansion of $\mathrm{HCI}$ as a discipline is significant and exceptional in its own way and has led to an increasingly remarkable relationship between humans and computers. It has become so complex and extensive, that the disciplines of which it is comprised, are made up of their own responses of disciplines [5]. In order to make the computer work well for humans, we need to know what make human close or communicate and human limitation. It will be mention in next section.

\section{Human Behaviors and Social Interactions}

Social influence means the effects of behavior and attitudes of one person to another. As for social interaction means that the behavior of one's influences each other. Behavior came from social inducements through the stimulation process. Factors make people like or dislike each other are closeness, similarities, differences, familiarity, balance, and advantagedisadvantage [6]. The behavior of surrounded people will be observed as the data in the social association. Any behavior will be presented toward the situation. Therefore, there is a social assessment process. Individuals may be agreeable to the group by changing 
their behaviors or beliefs accepting personal behavior. We learn about ourselves by studying the reactions of others to us, and by observing our own behavior.

Projected social influence caused by agreement to authority and persuasion to change attitudes which must rely on a reliable and satisfying communicator. In addition, the attitude may change in a conflict of ideas. The most intense social influence is brainwashing relationship between people according to the group behavior theory of Thibaut and Kelley [7] which are based on exploration of profits not complications. Interpersonal relationships will persevere when the profits or benefits are higher than the expectation level. Social interaction depends on social awareness which consists of impressions and identification of behavior. The impression includes the character of the person (stereotype), the first impression, the core style, and the story. Identifying the cause of the behavior is the study of why the person is showing an opinion which may be caused by the person himself or the environment. Interactions within the group cause different roles of members and the level of risk of getting out of society that is higher than being alone. Relationship between groups like interpersonal relationships are different. There is no member who has absolute power in the group. Besides, conflicts between groups cause unity within the group.

The importance of interaction within the environment. The environment is everything that is around human beings, both living and non-living. Including concrete (can be seen and seen) and abstract (such as, culture, tradition, beliefs) have a connected influence is an influence to support each other. The impact of one reason will have another part to create or destroy. Inevitably Environment is a cycle that related to the whole system. The environment of human is divided into two parts: 1. Natural Environment such as forests, mountains, soil, water, air, resources. 2. Man-made environments such as urban communities, construction, historic sites, arts, traditions and culture.

Another type of social interaction is the interaction between people and the social and physical environment. This has developed into another field of social psychology called environmental psychology. The interaction between people and the environment is formed because many environments are created by individuals. These environments also influence the behavior of individuals including density and noise as follows.

The density is caused by the rapid increase in population and due to the migration of many people into restricted areas. For example, in large cities, the study of many psychologists shows the relationship between density of the people. The nature of the limitations such as mental health, dementia and crime, where the population density is high. There will be a high rate of people with mental deterioration and high crime. Also found that high density sources and there are high criminals. Rural people experience natural drought. Liabilities and no livelihoods cause poverty, and the flow of the countryside entering the major cities. In addition to the density must be corrected by eliminating the poverty of rural people. Some psychologists have distinguished between the density and the crowd by saying that density is a physical condition, meaning the number of people per population is a psychological condition. The density does not necessarily cause the crowd condition, such as in the stadium or in listening to music with high density. It does not cause discomfort (Not in crowded conditions). If people watch sports or listen to a little music, it may be fun. People who are live in a dense place for a long time will be able to adjust themselves to live in that society but will cause frustration easily.

When in high density, another problem that occurs is noise pollution. If people live in there, although only a short time, it will find that they have changed in both physical and behavioral. The physical characteristics that change is that the heart will beat faster and have more sensitivity stimuli. The behavior that has changed is the ability to solve problems. When the noise is stopped, the various characteristics go into normal conditions. There are studies in young children found that children who live in very noisy places will have the ability to read and distinct the sound. These abilities are lower than children who live in a more peaceful place. Besides the sound, temperature is an environment that influences a person's behavior. In fact, Temperature does not directly influence behavior. But the temperature causes physical changes and emotional conditions, such as heat, causing damage to the body.

Social interaction also is a study of individual behavior. Influencing each other is a two-way process. It will be the social relationship, social awareness. Interaction are formed in groups and with the environment, also with social relations.

The basis of social interaction is relationship between two people, such as teacher-student, husband-wife, employee- employer, buyer- seller, etc. The behavior of both individuals has an influence on each other's actions, which is receiving various levels depending on the type of relationship. Husband and wife influence each other more than buyer and seller. Mother-daughter/son has more influence than employer-employee. To understand the social interaction process [7], we need to adapt the cost-effective theories. It has been applied to explain social relationships. By saying that the relationship between people is happening, exist, or terminate depends on the individual's analysis of the benefits and 
difficulties that will be received from one another. This examination happens every time, there is an intuitive collaboration. Then the person's responses can be seen as behaviors. The person will take to perform the actions that is evaluated to gain benefit more than lose benefits. If you think that greeting is good, then when you meet a friend, you will say hello. But if you say hi to a friend and the friend does not answer or ignore you, you do not say hello again and turn away. There was a greeting means the satisfaction of human. That is related to the relationship from the expectations or the level of comparison of the individual. The level of comparison in any interaction means the level of benefits that people expect or think they should receive. It is a result of experience, by experiencing examples from other people and how good the attitude is. People expect high benefits but if it doesn't work as he thinks, he will not be happy. Therefore, the satisfaction of interaction occurs when the benefits received are higher than the comparison level, or higher than the expectation level. Satisfaction make the person maintain that relationship until the benefits are lower than the expectation level then the unhappiness occurs. This may lead to termination of the relationship.

In some situation, if a person has the other options, for example; we may stop talking to the people who we meet in the elevator. If we rather think that talking to them is less useful, we have rather stay quiet. While the friends in elevator may continue to talk because the benefits received from the conversation are higher than expectations for them. The benefits that each person expects will be different.

Even though each person is different in each situation and mood, it depends on perception of a person at a moment as well. Besides the first impression of individuals also have certain characteristics as the "core". to create collective awareness faster. If this core style changes, then perception is changed. For example, if information is provided about one people who is smart with skills, diligence, warm, good judgment, reason, and caution. This person is often perceived as a good person and happy. But when dividing some words in the above set of information is changed from warm to cold. It appears that the perception of the person has changed immediately. If there are changes to other words, this warm and cold word is one of the core social perceptions.

Recognition of other people depends on the content of information that is relevant to that person. The impressions that occur will vary according to the story that we know, such as our perception of the aggression from the merciful person. It is different from the aggression from heartless people for those with high compassion. We often believe that the aggression that merciful people expresses, it is less intense than from the heartless people. The Merciful people may show only a bit of aggression or fierce words, but the heartless person may be very aggressive, showing aggression in dangerous ways such as wood, weapons, etc.

Another social perception is to identify the cause of the behavior. This is where a person tries to determine the cause of a person's behavior. One can determine the cause of a person's behavior in two ways: the first is the internal cause, for example, due to attitude, personality, emotions, etc. Another is caused by the environment or external causes; such as being threatened.

Human factors have influenced the identification of the causes of behavior as follows.

1) It will be different, if people have different behaviors when react to the various stimuli. The cause of the behavior may be caused by the environment, usually from their experiences. Mr. A. watched many movies and he is ok until he watched Titanic then he cried. It shows that the movie Titanic is sad (compare to other movies he watched).

2) it will be consensus, if a person behaves like other people, the environment is the cause of behavior. But if a person has a different individual behavior, it would show that the person was the cause of behavior, such as everyone who watched the movie Titanic, including Mr. $\mathrm{B}$, only Weep.

The reason everyone cried was not because of the film. Mr. A. may have similar experiences in the film, causing a lot of depression. The cause of crying is the cause of the person himself not from the movie.

3 ) it will be consistency, if a person has a behavior in a situation, regularly the cause of behavior may be caused by a person or environment. But if the behavior is not consistent. Showing the cause of behavior from a person such as Mr. A. watched the movie Titanic many times and not crying, except this time. It shows that today's mood of Mr. A. may not be normal, but if Mr. B cries every time, he watches a movie, it may show that the movie is sad, or Mr. B. is a sensitive person.

Social awareness affects social interaction. Because if we know other people. Our reaction or behavior to that person would be consistent with our perception. The computer is a social actor. One of the best-known paradigms that serve as the theoretical framework for the study is the computer as a social worker (CASA). [9] It states that those phenomena found in social sciences such as the norms of politeness, the norms of exchange [10], or the norms of self-disclosure to each other [11] can be observed during human-computer interaction tests. The use of personality to our computers and our similarities. (That is, introvert people like to interact with computers that show introverted characteristics.) [12] Other studies have shown that when the 
interdependence between humans and computers is created in experimental situations, participants see that these computers Is a teammate who feels more collaborative, perceives computers more like themselves [13] Social categorization and pattern also play a role in human-computer interaction: Participants rate computers with voices like women. The output sound is more reliable when talking about dating and romantic relationships. More reliable in the topic of computers and technology. In addition, the male voters as well as the overall were more capable and friendly [14] chatbots.

The results shown above are not only Besides, has a meaning for social sciences then is relevant in our daily lives as well It is possible that many of us have met with computer programs whose social behavior is rather trusted or popular, and society. Most of these programs are chatbots called: artificial intelligence programs that simulate conversations like human.

In the last few decades, the demand for social tools has increased tremendously. According to social design theory [15] humans ('users' or 'customers' depend on space) have many problems with machines that can be resolved or alleviated with simple social gestures from the device. Therefore, if we can ask for approval from our computer and it can give us feedback about what he understands and the information needed to complete the work, our interaction will be more efficient and enjoyable.

This understanding makes it understand that chatbots have been a center of attention: since its initial creation in 1966. [16] Many people have attempted to develop artificial agents with perfect interaction capabilities and the use of abundant natural language. The first chatbot was Elisa, who soon imitated the non-commanding therapist and was followed by PARRY, which used the methods of schizophrenic, paranoid, paranoid patients to Soweto bent my interlocutor about his humanity. Since then, with the help of linguists and social sciences, experts have created more reliable chat bots.

The main venue for the Chatbot test is the Loebner Prize held every year. The competition was founded by Dr. Hugh Lobner in 1990 and the competing chatbots must show their ability to talk like humans. The competition is based on Turing's test, named Alan Turing, who proposed the test in a 1950 paper entitled Machinery and Intelligence. In this article, he asks himself and readers about the ability of Thinking Machine He suggested that if the answers from that computer could not be separated from humans, the computer would pass the Turing test. In agreement with this during the Loebner Prize competition, the judge conducted a conversation through a computer keyboard, computer program, and humans. In response to the judges deciding who and which programs are the most human, won that year's prize. Today, the most successful chatbot is the Mitsuku Loebner Prize winner three times, but the highest prize remains. Never give to anyone for the first software, the judge could not distinguish it from the real human in the Turing test, which includes understanding text, images and listening. It won 100.000 USD. The annual competition ends. There are major findings [8], that cause the change in social interaction.

A summary of some of the interesting conclusions about human interaction with social media in year 2019:

- Facebook declining: There's a clear indication that marketers are diversifying away from Facebook. For the first time in the last 5 years, Facebook lost share as the most important platform for marketers, dropping from $67 \%$ in 2018 to $61 \%$ in 2019 . One in ten marketers indicated they'll be decreasing their organic marketing on Facebook. Only $51 \%$ of marketers plan on increasing their Facebook organic activities, down from $62 \%$ in 2018.

- Interest in Messenger bots declining: Messenger bots haven't caught on with marketers. Only $14 \%$ of marketers are using bots (down from $15 \%$ in 2018). Only $32 \%$ of marketers plan on increasing their bot activities, down from $39 \%$ in 2018 . Interest in learning more about Messenger bots dropped to $45 \%$ from $70 \%$ in 2018.

- Instagram is popular: Seventy-three percent of marketers are using Instagram, up from 66\% in 2018. It's the second most important social platform for marketing (behind Facebook) and surpassed LinkedIn for the first time. A significant $69 \%$ of marketers plan on increasing their Instagram organic activities over the next 12 months. Instagram is the number-one platform marketers want to learn more about, surpassing Facebook for the first time.

- Engagement matters most: How to achieve better engagement, it is the top question that the marketers want to answer. This is likely in reaction to Facebook news feed changes made in early 2018 that incentivize meaningful social interactions.

- YouTube interest is high: A significant $71 \%$ of marketers plan on increasing their use of YouTube video and $75 \%$ want to learn more about marketing on the platform. YouTube is the number-one video channel, used by $57 \%$ of marketers.

- Facebook dominance: A very significant $94 \%$ of marketers use Facebook (followed by Instagram at $73 \%$ ). Sixty-one percent of marketers claim Facebook is their most important social platform. Facebook ads are used by $72 \%$ of marketers and $59 \%$ plan on increasing their use of Facebook ads over the next 12 months. The above summary is just a taste of what's in this report. On 
the following pages, you'll find more than 60 charts that visually convey some fascinating findings.

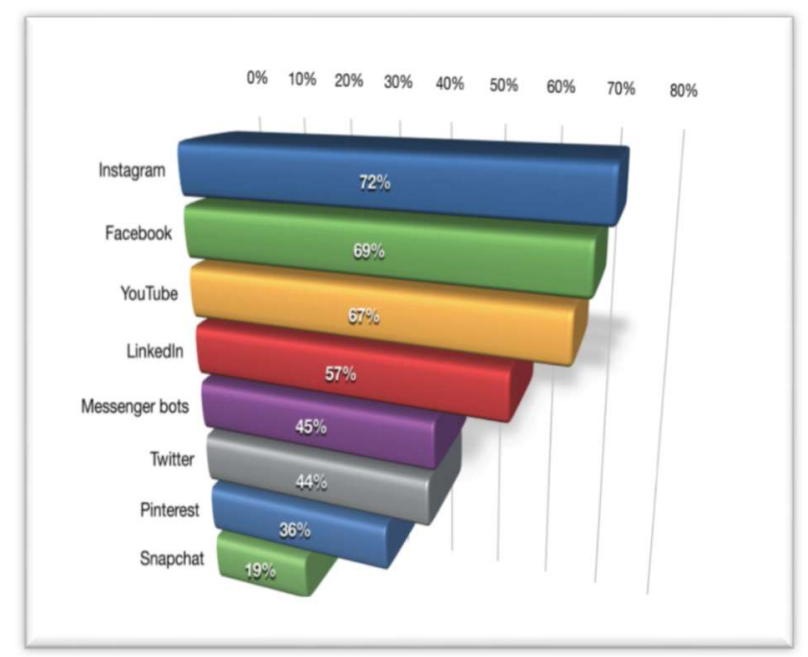

Figure 1. Social media platforms marketers want to learn more about [8]

\section{Technology Impacts}

Technology has transformed our lives, accumulative the speed of time. We, as humans, have invented and developed technologies to make the best of our lives. Now the technology can facilitate human to have a better life, while there are so many negative issues from using technology. Technology has been created from intelligence, curiosity, creativity of human. But human have to smart enough to manipulate the technology.

Eventually, the internet changed the approach we deliberate about information. The fact that we do not know anything that is widely available in the general understanding of humans can no longer threaten humans into being deceived. If we do not know what other people are doing and there are enough ways around the internet's common collective that allow us to go to known sources [23].

As technology has changed our lives in so many ways as follows:

1.1 Life, learning, anytime, anywhere (Ubiquitous life) with the urban lifestyle that is dynamic and fast changing. The computer system plays a huge role in facilitating and supporting all forms of life. Various types of portable communication devices are the fifth factor that helps reduce the existing time constraints, whether it is consumerism, transactions and communication. From now on, can be done 24 hours a day. In addition, the trend of digital society and economy (Digital society and economy).

1.2 Connected track.

Dense traffic problems and traffic jam caused from using private cars to travel to the inner city. It will be replaced by a rail transport system that connects the area between districts and is the main choice for travel of big city people. In addition, the development of the area around the BTS station according to the concept is to emphasize the connection with the surrounding area and to encourage people to use foot and bicycle in daily life more.

\subsection{Freedom of work}

Online working will result in a new generation of flexible working ways. Not attached to the time frame Not attached to the organization Not attached to the place. Therefore, making the location of the residence not an important factor in the work. The tendency of evaluating work values is primarily based on performance based.

\subsection{Convenient Public service}

In general, the metropolitan city (Megacity) should be able to have fewer cars in the inner area. Therefore, the public and private sectors focus on providing one stop service by planning for service points in all areas and various channels. It allows people to access services such as government medical services that patients and the general public can easily access services and counter service Online service.

\subsection{Integrated cultural tourism}

The result of the restoration of the old area will result in higher land prices. There is a new tourism business in response to changes in tourism behavior. It emphasizes access to deep knowledge to gain a more spatial experience than quantitative tourism that focuses on numbers of attractions. as a result, the land business changed from trading to long-term land lease. The opportunity for foreign entrepreneurs to complete the service business.

1.6 urban industries

To support the change in the structure of society in the future, whether changing the proportion of the population to be an aging society and the number of foreigners who flow into and work in Thailand due to joining the long-term ASEAN Community (AEC). Many new industries will have developed in various ways to meet such lifestyle such as cultural tourism industry, health and recreation that are not the hustle, relaxation, or nutrition that people turn to pay more attention to health.

1.7 Diversified environmentally friendly energy sources.

Awareness of being a pollution-free society and using renewable energy in the future. It will result in the reduction of fossil energy use and are substituted by alternative energy such as improved battery storage technology (Battery) 
1.8 Land use and area for population structure, Big city New Land \& Space for New residents

Restrictions in terms of area size and the population of the elderly and workers or low-income people will increase in the future. This factor will drive the trend of land use as a housing with the development of an old building to be a residence, including a sharing housing (Space / time).

1.9 Cosmopolitan's New Normal

The cultural integration from the ASEAN Community (AEC) and technological progress is an important factor in causing social interaction in a new way. The lifestyle will be more different according to income, tastes and ideals, aiming to seek and develop a specific area of identity with individuality at a higher level.

1.10 Inclusive development

To respond to equality in society on each side Development will be based on the opportunity to create opportunities for all groups in society, whether it is the development of a comprehensive transportation system. Development of data access rights and equality in the development of digital infrastructure systems and the development of space for social interaction.

Humans tend to socialize with friends. Nevertheless, humans ready to recognize inanimate objects as social representatives, especially computers, are good for personal settings as they look like humans [8]: They give words for results [17] they interact [6] and they have the same role. It is clear to response societies with their actions. In situations of uncertainty, unfamiliar or ambiguous, we tend to use categories. Among those we know best defining human characteristics (we know very well) with computers (we are not safe.) Another possible explanation is that humans do not respond to society with computers. It is the human expert behind software, but research shows that people do not differentiate between two software programs and two computers. They will act like a computer as a social agent. [8] Moon and Nass offer three explanations: they say that some context directs, activates certain scripts that lead to inappropriate behavior. Computers have many cues that they should be treated like humans, so most of us ignore the opposite and behave as if they were our colleagues. [18] The fact that humans interact with computer in society creates a base for the practice in which the study of social psychology is a model of human-computer interaction.

\section{4. $\mathrm{HCl}$, Information Technology and Changes}

Social changes are rising, as also the $\mathrm{HCI}$ is more and more significant engaged to the society. Trends of global society change in HCI, it makes the distribution of information fast in all directions and has a promptly response system. For this reason, the impact on economic, political, and social changes the result of advances in HCI, also has caused so many major changes in trends.

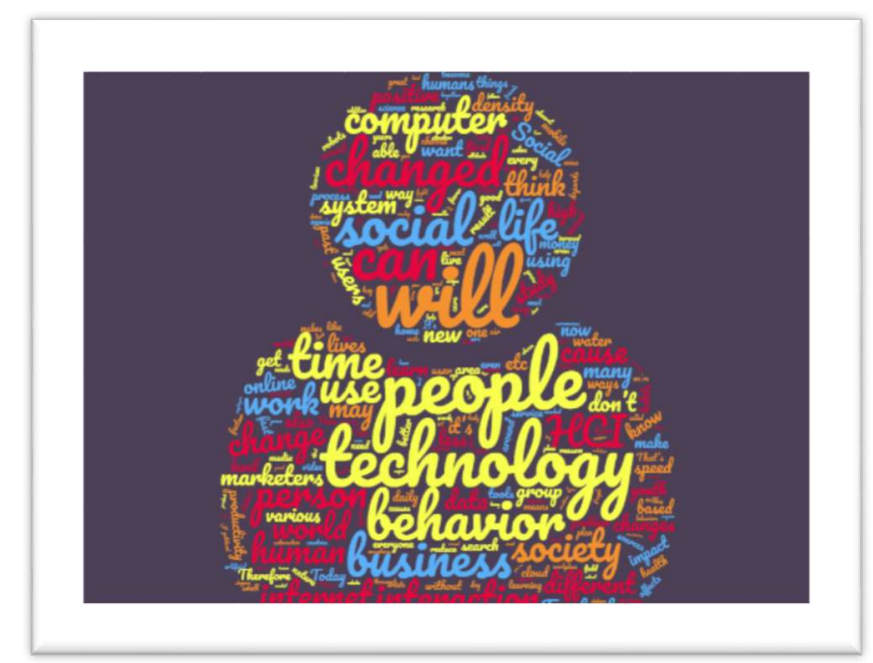

Figure 2. Words cloud of the content of the information about human and technology

Society had changed from industrial society to information society. The world society has changed tremendously. From agricultural society that has cultivated and created agricultural products, causing the building of houses as primary sources. Later, it is necessary to produce many products in the cheap costs. Therefore, having to turn to produce into industrial designs, causing the living conditions of humans to change into urban society. There is a group of residents in the city. There is an industry as a production base. Industrial society has operated and changed into the information society. Business operations use information widely. There is a new word that cyberspace has conducted various activities such as talking over the internet, buying products and services, etc.

HCI is a discipline that responds to the needs of individual users, such as communication, watching television, radio. In the past, when we turn on the television or radio receiver, we cannot choose according to what we need. If we do not satisfy, just select the new station. The trend from now on will change in a manner called on-demand. We will choose television programs to watch, choose to listen the radio program as needed. 
If the education system has education on demand or we call e-learning or MOOC (such as SMART MOOC ${ }^{1}$ in Fig.3), it is possible to choose to study as needed. Responding to the needs is a possible way because the technology has progressed until the communication system can be used to meet human needs.

Technology always has been used in working conditions in all locations and all the time. When communication is progressive and widespread, Interaction over the network makes interaction possible. A video conferencing system on the network system, is the trading system on the network. The nature of these operations allows users to expand the possibility of activities everywhere 24 hours. It spreads closer to the client and with advanced discipline, Service will spread even more at home. In the future, social work will spread until some jobs may sit at home or anywhere and at any time.

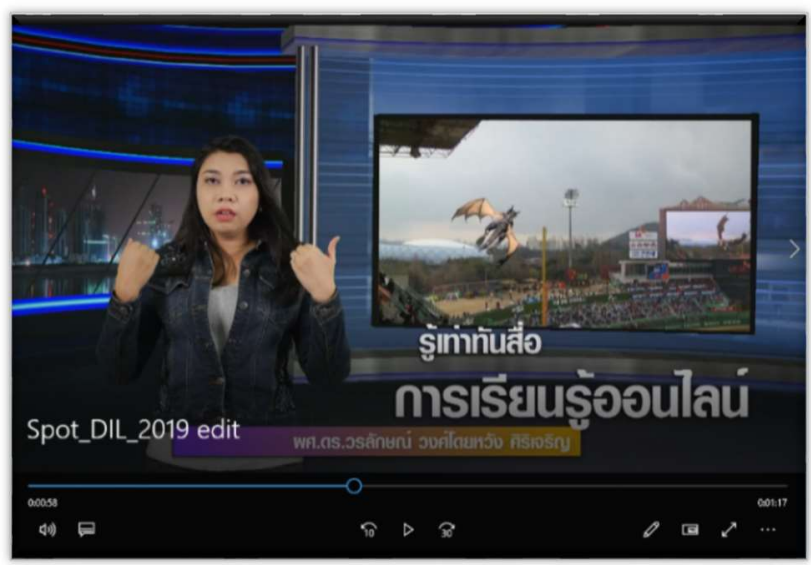

Figure 3. SMART MOOC, DIL literacy Module 3

Information technology causes the economic system to change from the local system to the global economy. Economic system which originally had limited scope within the country, now it spreads to the world economy around the world, there will be a circulation of goods exchange. Wide-ranging and fast service infrastructure has contributed to the implementation of a wider scope. The economic system of all countries in the world is linked and affects each other.

The new way of human computer interaction causes the organization to have a binding nature within the organization to become more interacted. Originally, the organization was placed in a hierarchy have a command line from top to bottom. But when two-way communication and news spread better. The use of computer networks in the organization is bound to be a work group. The value of the organization with HCI organizational structure is changed from the original. It tends to create organizations as networks that have some more horizontal command Business units will be smaller. connected with other business units as a network the organizational structure has changed according to the current of discipline.

The better interaction is made by computers, cause the better a long-term action plan. It also makes the decision-making process more prudent. Originally, judging the problem may have a few ways to choose, such as having one answer, yes and no, but with information that supports decision making the way of thinking about the problem has changed decision makers have more choices and have better coverage to judge problems.

$\mathrm{HCI}$ is the discipline that plays an important role in every industry Therefore affecting social, cultural, moral, educational, economic and political changes imagine that now we can watch news, watch TV programs that are distributed via satellite of various countries around the world. We can receive news immediately. We use the internet to communicate with each other. Besides, it connects with people around the world. Therefore, the trend of cultural, economic, social and political changes has become a more global society. The status of the development of chatbots has not yet reached its goal: software that can emulate human behavior completely has not yet arrived. Nonetheless an interesting question has arisen: what can we do with a program that meets all conditions to appear as humans? Will this situation respond the same to us? we will continue to respond to society, will we remain polite, will we continue to use our social conventions? Will we dare yell at it or show our offense?

\section{Conclusion}

We already know that humanity is ready to socialize with computers and computer programs. Our characteristics mean that it is possible to use the discoveries of social psychology and human-computer interaction. We also know that the artificial intelligence industry has begun to get involved in our work by creating the ultimate in social media such as chatbots or virtual assistant or human-like conversation. The main question is: Is this enough that social machines can mimic human behavior for sympathy and trust?

The official test site for virtual assistant $\mathrm{s}$ promotes a clear idea that the most virtual assistant is the best human like conversation, on the other hand, there is a high possibility that creating a completely human chatbot will have the opposite effect of receiving it.

${ }^{1}$ http://smartmooc.org/ 
Humans are too honest. [19] If there is very little contextual guidance in our interaction, computer programs do not need to pretend to be humans: it serves for social behavior. Users share information about themselves, respond politely to politeness, show uncertainty about certain things and more.

We are surrounded by machines and computer programs in our daily lives, and because artificial intelligence is one of the fastest developed areas of human technology, it is important to understand our relationship with them. Human-computer interaction may show an essential part in the future of humanity.

\section{References}

[1] Rizzolatti G. and Craighero, L. 2004. "The Mirror-Neuron System,” Ann. Rev. Neuroscience, vol. 27, pp. 169-192.

[2] Pickles, J. 1982. An Introduction to the Physiology of Hearing. Academic Press.

[3] Richmond V. and McCroskey, J. 2012. Nonverbal Behaviors in Interpersonal Relations. Allyn and Bacon, 1995) in: Vinciarelli, A., Pantic, M., Heylen, D., Pelachaud, C., Poggi, I., D'Errico, F., \& Schroeder, M. (2012). Bridging the gap between social animal and unsocial machine: A survey of social signal processing. IEEE Transactions on Affective Computing, 3(1), 69-87.

[4] Herrmann, E., Call, J., Hernández-Lloreda, M. V., Hare, B., \& Tomasello, M. 2007. Humans have evolved specialized skills of social cognition: The cultural intelligence hypothesis. Science, 317(5843), 1360-1366.

[5] https://www.algrim.co, 2019. How HCI (Human-Computer Interaction) Has Evolved Alongside Technology. Retrieved from: https://www.algrim.co/posts/51-how-hci-humancomputer-interaction-has-evolved-alongside-technology

[6] Sprecher, Susan \& Treger, Stanislav \& Wondra, Joshua. 2013. Effects of self-disclosure role on liking, closeness, and other impressions in get-acquainted interactions. Journal of Social and Personal Relationships. 30. $10.1177 / 0265407512459033$.

[7] Thibaut, J. W.; Kelley, H. H. 1959. The social psychology of groups. New York: Wiley. ISBN 9780887386336.;

[8] Nass, C., \& Moon, Y. 2000. Machines and mindlessness: Social responses to computers. Journal of social issues, 56(1), 81-103.
[9] Nass, C., Steuer, J., \& Tauber, E. R. 1994. Computers are social actors. In Proceedings of the SIGCHI conference on Human factors in computing systems (pp. 72-78). ACM.

[10] Fogg, B. J., \& Nass, C. 1997. How users reciprocate to computers: an experiment that demonstrates behavior change. In CHI'97 extended abstracts on Human factors in computing systems (pp. 331-332). ACM

[11] Moon, Y. 2000. Intimate exchanges: Using computers to elicit self-disclosure from consumers. Journal of consumer research, 26(4), 323-339.

[12] Moon, Y., \& Nass, C. 1996. How "real" are computer personalities? Psychological responses to personality types in human-computer interaction. Communication research, 23(6), 651-674.

[13] Nass, C., Fogg, B. J., \& Moon, Y. 1996. Can computers be teammates? International Journal of Human-Computer Studies, 45(6), 669-678.

[14] Nass, C., Moon, Y., \& Green, N. 1997. Are machines gender neutral? Gender-stereotypic responses to computers with voices. Journal of applied social psychology, 27(10), 864-876.

[15] http://www.jnd.org/ms/1.1\%20Sociable\%20Design.pdf

[16] Weizenbaum, J. 1966. Eliza - a computer program for the study of natural language communication between man and machine. Communication of the ACM, 9, 36-45.

[17] Sharma, V. K. 2017. Top 12 Examples, How Technology Has Changed Our Lives. Retrieved from: http://www.klientsolutech.com/examples-of-howtechnology-has-changed-our-lives/

[18] Nass, C., \& Moon, Y. 2000. Machines and mindlessness: Social responses to computers. Journal of social issues, 56(1), 81-103.

[19] Gray, K., \& Wegner, D. M. 2012. Feeling robots and human zombies: Mind perception and the uncanny valley. Cognition, 125(1), 125-130.

[20] Almosdi, F., Ujhelyi, A. 2019. Social Machines: Social Aspects of Human-Computer Interaction.

[21] Jones, M. 2019. Introduction. Retrieved from: https://www.cs.bham.ac.uk/ rxb/Teaching/HCI\%20II/intro. html

[22] Dix A. 2009. Human-Computer Interaction. In: LIU L., ÖZSU M.T. (eds) Encyclopedia of Database Systems. Springer, Boston, MA

[23] Rushkoff, D. 2019. 2010: HOW IS THE INTERNET CHANGING THE WAY YOU THINK? Retrieved from: https://www.edge.org/responses/how-is-the-internetchanging-the-way-you-think 